\title{
Reflexiones en torno a la
}

técnica del teatro foro $y$

\section{su papel en la mediación}

pedagógica

Reflections on the Technique of Forum Theater and Its Role in Pedagogical Mediation

Julio Barquero Alfaro ${ }^{l}$

Universidad Nacional

Costa Rica

Melissa María Chacón Céspedes ${ }^{2}$

Universidad Nacional

Costa Rica

\section{Resumen}

En el siguiente artículo se presenta un recurso de mediación pedagógica mediante la técnica del teatro foro en la Universidad Nacional. La técnica se utiliza como una herramienta colectiva de debate y reflexión grupal en torno a determinadas problemáticas sociales y cuyo objetivo es la representación de una obra de teatro corta, en la que se exponen situaciones opresivas y se logran reconocer los principales discursos y roles sociales presentes la vida cotidiana. La técnica se aplica con estudiantes de la universidad como continuación de dos cursos pasados cuyo nombre era Teatro del Oprimido: una perspectiva práctica del humanismo (2016-2018) y en el marco del proyecto Una ventana al teatro: aportes artísticos en la mediación pedagógica (2015-2017). Por lo tanto, esta técnica se realiza como medio para fomentar reflexión crítica y la intervención activa del público en busca de soluciones al problema expuesto en cada representación. El diálogo

$1 \quad$ Licenciado en Artes Escénicas, Maestría en Estudios Latinoamericanos con énfasis en Cultura y Desarrollo de la Universidad Nacional de Costa Rica. Académico de Estudios Generales, Universidad Nacional de Costa Rica. Correo electrónico: julio. barquero.alfaro@una.cr

2 Máster en Pedagogía con énfasis en Diversidad de Procesos Educativos, Licenciada en Artes Escénicas

y Publicidad. Es académica del Centro de Estudios Generales de la Universidad Nacional. Correo electrónico: melissa.chacon.cespedes@una.cr 
que se produce entre el arte teatral y la participación estudiantil construye un mayor sentido de comunidad, escucha y empatía, apelando a una concienciación social y mayor incidencia política en los diferentes espacios de acción académica.

Palabras claves: teatro foro; educación, mediación; juego teatral; pedagogía teatral.

\begin{abstract}
The following article presents a resource of pedagogical mediation through the technique of forum theater at the National University of Costa Rica. The technique is used as a collective tool of debate and group reflection around certain social problems, and whose objective is to represent a short play, in which oppressive situations are exposed, and the main discourses and social roles present in daily life are recognized. The technique is applied with university students as a continuation of two previous courses whose name was Theater of the Oppressed: a practical perspective of humanism (2016-2018) and within the framework of the project A Window to the Theater: Artistic Contributions in Pedagogical Mediation (2015-2017). Therefore, this technique is implemented as a means to encourage critical reflection and the active intervention of the public in search of solutions to the problem exposed in each performance. The dialog that takes place between theatrical art and student participation builds a greater sense of community, listening, and empathy, appealing to social awareness and greater political advocacy in the different spaces of academic action.
\end{abstract}

Keywords: theater; education, mediation; dramatic play; theatrical pedagogy.

\title{
Hacia una pedagogía basada en la democratización del teatro
}

Las reflexiones que se comparten en este documento se sustentan en el trabajo realizado en el Centro de Estudios Generales de la Universidad Nacional, específicamente, en el curso "Teatro del Oprimido: una perspectiva práctica del humanismo” (2016-2018) y en el proyecto “Una ventana al teatro: aportes artísticos en la mediación pedagógica” (2015-2017). Las inquietudes expresadas representan una búsqueda metodológica apoyada en la disciplina artística del teatro y en propuestas de mediación pedagógica desarrolladas con estudiantes universitarios.

La técnica del teatro Foro se podría describir como una herramienta colectiva de debate y reflexión grupal en torno a determinadas problemáticas sociales. Consiste en la representación de una obra de teatro corta, en la que se expongan situaciones opresivas y se logren reconocer los principales discursos y roles sociales presentes en el cotidiano vivir. La técnica fomenta la reflexión crítica y la intervención activa del público en busca de soluciones al problema expuesto. Este 
recurso es usado constantemente en los procesos de mediación en el aula o en procedimientos de producción teatral.

Las múltiples posibilidades de vínculo que existen entre las disciplinas artísticas y las demás áreas representan grandes oportunidades para fortalecer el trabajo en el aula. La exploración del lenguaje escénico cargado de símbolos, corporalidades y metáforas permite abordar de manera más compleja determinados contenidos académicos, al recurrir a elementos lúdicos y reflexivos que fomentan la interdisciplina, el diálogo de saberes, la empatía, creatividad, entre otros aportes intangibles que genera el teatro a sus participantes.

Por lo anterior, se considera como referentes teóricos aquellos relacionados con técnicas grupales escénicas y enfoques pedagógicos, como la necesidad de brindar procesos integrales con visión humanista. Entre las líneas de estudio que respaldan dicha reflexión, se toma en consideración los siguientes enfoques:

1. La capacidad que tienen todas las personas para expresar sus ideas, autoobservarse en situaciones cotidianas y la comunicación no verbal presente en el diario vivir son pilares que sustentan el concepto de teatro esencial propuesto por Augusto Boal en la estética del teatro oprimido. Al mismo tiempo, se subraya la necesidad de que dichas ideas sean compartidas y articuladas colectivamente.

2. Un método escénico democrático y sistematizado que dinamiza y colabora en los procesos articulatorios de creación artística, procurando objetivar aquellos procedimientos subjetivos de la creación. Este es el elemento que se abstrae de Enrique Buenaventura en su método de creación colectiva, como mecanismo teatral para fomentar las capacidades creadoras y el diálogo entre los participantes.

\section{Teatro del oprimido: La democratización del ciudadano}

Augusto Boal (1931-2009), dramaturgo, escritor y director de teatro, creó el teatro del oprimido a comienzos de los años 60. La idea de Boal fue romper la tradición burguesa y elitista del teatro, porque consideraba que la separación entre actores y espectadores responde a una suposición ideal que otorga a unos pocos el derecho a la palabra y la acción, mientras censura a los demás al silencio, la pasividad y la oscuridad. Propone una ruptura de ese reparto de roles, permitiendo que los espectadores puedan intervenir activamente en la representación. 
También muestra en el teatro las distintas formas de opresión del ser humano y recurre a aquel como un medio de concientización e instrumento ideológico que conduzca al cambio, al análisis de las causas y vicios sociales. Su objetivo es transformar al espectador en protagonista de la acción dramática, para ayudarlo a preparar acciones reales que lo conduzcan a la propia liberación. Boal parte del principio del teatro como lenguaje que puede ser usado por cualquier persona, tan pronto como se apropia de los medios de producción. El concepto boaliano de teatro esencial plantea: "todo ser humano es teatro y por ende toda acción humana es considerada como tal, ya que en el mismo espacio y contexto cada ser humano es capaz de observar la situación y de observarse a sí mismo en situación" (Boal, 2004, p. 7).

Boal buscó un teatro con el propósito de humanizar a la humanidad, su finalidad es hacer accesible el lenguaje teatral como método pedagógico y forma de conocimiento para la transformación de la realidad social, su propuesta presenta aspectos pedagógicos, sociales, culturales, políticos y terapéuticos. La metodología de teatro del oprimido puede ser utilizada en el proceso educacional, por permitir el intercambio de conocimientos y experiencias. Es así como se convirtió en un instrumento que facilitó las discusiones de los problemas sociales y de intervención socioeducativa, uno de sus principales objetivos era ayudar a restaurar el diálogo entre seres humanos y la comunicación.

\section{Creación colectiva: crear es sinónimo de escuchar}

Enrique Buenaventura (1925-2003), narrador, actor, director y ensayista colombiano, sistematiza a lo largo de su trabajo teatral con el colectivo Teatro Experimental de Cali, entre la década de los 60 y 80. Surgió tras la necesidad de articular temáticas entre las problemáticas cotidianas e históricas que han determinado los procesos de identidad, al mismo tiempo que buscó solucionar problemas de montaje escénico, con el objetivo de ofrecer una nueva propuesta teatral para el público.

Dicha propuesta supera los intereses estéticos de una puesta en escena y se funda, principalmente, en el modo dialógico en el que se democratizan los roles, participaciones y responsabilidades en el colectivo teatral, con el objetivo de llevar, en el nivel interno, una muestra de las posibilidades comunicativas, fundamentadas en el comportamiento que el equipo de trabajo experimentó y registró. Así, se pretende demostrar que las demás esferas de la vida cotidiana podrían validar la misma técnica y solucionar tanto la dinámica social como sus problemáticas derivadas, desde las alteraciones comunicativas. En otras palabras, 
el producto escénico es reflejo de la dinámica social interna del colectivo, citando a Márceles (1977):

Se trabaja sobre elementos concretamente experimentales que han surgido de la búsqueda de un método de montaje escénico que traduzca las necesidades de proyectar una versión más verídica y humana de nuestra historia y que, a su vez, trascienda a una audiencia receptiva y crítica. (p.36)

Uno de los elementos importantes de la propuesta de Buenaventura es la noción de desaparecer el rol de autor o director de la actividad teatral y sus procesos de construcción, ya que dicho pronunciamiento establece claramente roles de poder y jerarquía interna, y es precisamente la noción de participación horizontal en la que está fundamentado el proceso de elaboración, construcción, definición y sistematización de los resultados o productos creados colectivamente.

Buenaventura consideró que la técnica de la improvisación es un elemento clave en la elaboración del material escénico como aspecto de primigenia importancia, al ser un estímulo para que el grupo construyera desde sus referentes históricos y vivenciales aquellas dramatizaciones que evidenciarían el bagaje de cada participante. He ahí lo fundamental de la colectividad en lo teatral, ya que, tal y como lo expresa la artista contemporánea Teresa Marín, al analizar la creación colectiva como espacio donde se rompe la individualidad siempre ligada a los procesos de creación, expresa que el grupo teatral "es un conjunto de personas que interactúan entre sí durante un periodo de tiempo y que se reconocen como interdependientes entre ellos en relación a un objetivo común, en este caso vinculado al arte y su divulgación” (Marín, 2007, p. 21).

La corriente poética del teatro del oprimido afirma que todas las personas pueden hacer teatro, porque lo son. Uno de los principios básicos del teatro latinoamericano de carácter social recae, principalmente, en la premisa de que todos los seres humanos contamos con la capacidad de autoobservación de nuestras acciones; por lo tanto, cumplimos un rol dual en el que somos actores y espectadores de nuestros propios contextos. Por ello, tomando en consideración que estas reflexiones apuntan a la necesidad de ampliar aquellas perspectivas educativas de índole bancaria en las que tradicionalmente hemos sido educados y hasta domesticados, inmersos en sistemas tradicionales de exclusión, competencia y castración política, se requiere partir del principio fundamental del teatro del oprimido: todas las personas somos actores en potencia, por tanto, agentes de cambio en un mundo que requiere una mayor participación política y colectiva. 


\section{Teatro foro como canal de escucha, pensamiento crítico y sentido de colectividad}

La propuesta del teatro foro se caracteriza por el fomento de la capacidad de diálogo, concienciación y transformación social, en busca de soluciones: "transformar al espectador en protagonista de la acción dramática para ayudar al espectador a preparar acciones reales que lo conduzcan a la propia liberación" (Boal, 2003, p. 17); el teatro como lenguaje que puede ser usado por cualquier persona, tan pronto como se apropie de sus medios expresivos. El papel pedagógico que se propone cumplir, por medio de una serie de ejercicios, juegos, técnicas y formas teatrales, busca conocer la realidad para transformarla.

Según Boal (2002), específicamente la técnica de teatro foro, permite al participante intervenir en la escena y modificarla, proponiendo una discusión profunda y fecunda, al crear un tipo de juego y diálogo entre el público participante. Es decir, no hay lugar para el espectador pasivo, se rompe la división entre actor-espectador y sus tradicionales funciones, el espectador toma la acción y se convierte en transformador de la acción dramática.

Se toma en consideración el aporte conceptual del poder según Michel Foucault. Al hacer accesible el lenguaje teatral como método pedagógico y forma de conocimiento para la transformación de la realidad social, se debe tomar en cuenta que los seres humanos son constituidos en sujetos insertos en modelos cambiantes de poder y sus relaciones dentro de la sociedad, un poder expresado en diversas manifestaciones de lo cotidiano. Por lo tanto, desarrollar propuestas teatrales bajo este enfoque permite construir procesos participativos más conscientes y críticos en el aula.

Las relaciones de poder, complejo vínculo estratégico, se encuentran estrechamente ligadas a las familiares, sexuales, productivas, y al área educacional; íntimamente enlazadas y desempeñando un papel de condicionante y condicionado: "Creo que no existe un único poder en la sociedad, sino que existen relaciones de poder extraordinariamente numerosas, múltiples, en diferentes ámbitos, en los que unas se apoyan en otras y en las que unas se oponen a otras" (Foucault, 1998, p. 29).

Para comprender mejor dichas relaciones de poder, se recurre al concepto de teatro épico de Bertold Brecht. Su objetivo era presentar ideas e invitar al público a hacer juicios acerca de ellas, más allá del entretenimiento o mimetismo de la realidad; de ahí surge el concepto llamado distanciamiento. 
El dramaturgo argentino Jorge Saura (2007), en su libro Actores y actuación, menciona que el distanciamiento fue empleado para mantener al espectador a distancia de determinados procesos representados. Dicha técnica tenía por objeto colocar en una actitud inquisidora y crítica frente al proceso representado.

Para Freire, el sistema educativo tradicional se ha encargado de generar mayor pasividad, haciendo que los oprimidos se adapten al mundo y más lejos de transformar la realidad. La acción o praxis es el elemento generador para que los hombres actúen en el mundo, en busca de su humanización y liberación:

Si los seres humanos fueran seres totalmente determinados y no seres "programados para aprender" no habría por qué apelar en la práctica educativa a la capacidad crítica del educando. No habría por qué hablar de educación para la decisión, para la liberación. (Freire, 2001, p. 49)

La educación bancaria, llamada así por Freire, es un instrumento de la opresión, ya que pretende transformar la mentalidad de los educandos y no la situación en la que se encuentran. Freire niega el sistema unidireccional propuesto en este método educativo, dado que la comunicación de ida y vuelta elimina la separación entre educadores y educandos, creando así un proceso educativo. Dicha contrapuesta es llamada educación problematizadora, la cual apunta claramente hacia la liberación y la independencia, al destruir la pasividad del educando e incitar la búsqueda de la transformación de la realidad, en la que opresor y oprimido encontrarán la liberación humanizándose.

Por todo lo anterior, la premisa fundamental del teatro del oprimido:

El Teatro del Oprimido es un espejo donde podemos penetrar y si no nos gusta nuestra imagen reflejada en él, podemos transformarla, esculpirla de nuevo según nuestros deseos, porque el acto de transformar es trasformador: ¡Al transformarla, nos transformamos a nosotros mismos! (Boal, 2004, p. 37)

Se logra concatenar como base del proceso la importancia de recurrir a experiencias teatrales que se planteen el concepto de educación y de participación ciudadana en espacios universitarios, brindando una mirada proactiva y herramientas de cambio a estudiantes con carreras vinculantes a la técnica, como sociología, educación, psicología, por citar algunas. Uno de los objetivos del proceso formativo fue democratizar la palabra, accionar la posibilidad de cambio por medio de las intervenciones y propuestas dadas por cada estudiante. 
El teatro del oprimido se apoya en la pedagogía del oprimido y plantea que todas las relaciones humanas debieran ser de tipo dialógico: entre hombres y mujeres, entre etnias, familias, grupos y naciones; el coloquio debiera siempre prevalecer, ya que todos los diálogos tienen la tendencia de transformarse en monólogos, los cuales crean la relación opresores-oprimidos. Reconociendo esta realidad, el principio fundamental del teatro del oprimido es ayudar a restaurar las relaciones entre seres humanos. La propuesta de Foucault sobre el concepto de poder se traduce en las relaciones humanas expresadas en el contenido teatral propuesto en la técnica y que logra en la audiencia la identificación de problemáticas inmediatas, así como el espacio de encuentro y diálogo para abordarlas.

\section{Papel del comodín o facilitador del proceso}

La técnica de teatro foro plantea un rol llamado comodín, quien es el responsable de canalizar las sesiones entre el público y el grupo de actores que dialogan en la dinámica teatral presentada. El comodín conduce y fomenta tanto las intervenciones como las reflexiones sobre las problemáticas sociales mostradas; al mismo tiempo, es un investigador y facilitador de procesos creativos y críticos que la técnica ofrece.

El facilitador debe ser una persona receptiva, comprender que todo grupo social posee características particulares, necesidades personales; todo grupo social responde a una serie de factores externos que le acompañan, como espacio físico, variables de edad, condición económica, clima, estados anímicos y presiones personales/laborales. Lo anterior es el material humano con el que el facilitador dispone para trabajar y con el que la dinámica teatral cuenta para su ejecución.

Hablar de un facilitador receptivo es referirse a la responsabilidad que recae sobre él, ya que debe "escanear" las características del colectivo para poder utilizar sus recursos pedagógicos e iniciar procesos de búsqueda, en los cuales logre conseguir sus objetivos académicos (en este caso específico, el proyecto de graduación), al mismo tiempo que desarrolla sensibilidad para identificar el progreso o retroceso en las destrezas y actitudes del colectivo, según los recursos utilizados.

El instructor es preciso que escuche, sienta, observe y accione el modo aplicado y las reacciones mostradas. Se concluye que el facilitador debe saber identificar la balanza y tener capacidad objetiva de decisión en función del proceso, en donde aquellos aspectos que demanden mayor tiempo, explicación, modo o dinámica deben ser detectados, para un mejoramiento de la propuesta de trabajo y así solventar las necesidades que los participantes expresan en su dinámica grupal. 
El equilibrio entre "no imponer" y la responsabilidad de encauzar un proyecto académico fueron uno de los logros que generaron más trabajo y dualidad, pero la progresividad del taller y las acciones de prueba-error convirtieron dicha limitación en un alcance.

El facilitador necesita ser una persona motivadora que invite a cada integrante del colectivo a participar, disfrutar y aprender del quehacer teatral, en el que cada personalidad va a ir adaptándose, disponiéndose y descubriendo una serie de cualidades y destrezas que este tipo de proceso teatral les ofrece. El facilitador es el responsable de estimular a cada individuo a no solo participar, sino a aprehender de cada elemento nuevo que su cuerpo y mente vaya descubriendo.

Además, el facilitador debe permanecer en constante distanciamiento de su rol, tener la capacidad objetiva para analizar su subjetividad reflejada en decisiones, modo de comunicarse, dirección y guía del grupo, así como de la función que cumple como tal en el proceso. La autoobservación es un recurso apto para ampliar la percepción de lo que se comunica consciente o inconscientemente como responsable de un grupo de participantes.

El rol de comodines como eje transversal del rol de facilitadores experimentó etapas de debilidad e inseguridad en su ejecución y dominio. Elementos como la falta de congruencia en las reglas hacen concluir que es necesario que los espectadores reciban, de manera más concreta, clara y congruente, las reglas del juego al hacer teatro foro, pues, de este modo, no se crean limitaciones y confusiones a la hora ni en el modo de participar.

El comodín debe aprovechar los espacios de interacción con el público para un mejor empoderamiento de la sesión. Como ejemplo de este, se menciona lo fundamental de que los espectadores tengan oportunidad de decidir con cuál de las escenas mostradas prefieren iniciar.

La importancia de brindar un cierre final y reflexivo del teatro foro es otro aspecto fundamental en estas sesiones, pues es el espacio para incentivar a los espectadores a que compartan sus experiencias vividas, buscando visualizar la dinámica de lo mostrado ante la vida real y sus múltiples asociaciones. Además, se trata de un espacio en el que los implicados logran traducir en palabras el material sensorial que la práctica les generó; es, al mismo tiempo, un encuentro de las distintas percepciones que el público tiene ante temáticas sociales específicas y, sobre todo, la identificación y concientización social acerca de ellas. 
El teatro foro no es solo pensar en las opresiones del mundo o quejarse de todo lo malo que sucede; es aprender de uno mismo para crear en colectivo, saber escuchar, saber accionar, estimular la expresión e imaginación y generar reflexión.

El juego es un elemento primordial para despertar la confianza, la interacción grupal y la desinhibición, antes de profundizar en conceptos técnicos; para esto se debe proponer una estructura metodológica con objetivos claros, juegos acumulativos y consecutivos, en la que se logre trabajar sobre tareas concretas.

La experiencia buscó articular diferentes líneas de estudio, por medio del abordaje metodológico descrito anteriormente. Este se caracteriza por la participación colectiva, la reflexión crítica y la proyección de la población estudiantil universitaria, como sujeto protagonista de un proyecto, el cual utilizó herramientas artísticas como recursos para fortalecer la concientización social en el tratamiento de determinadas temáticas.

La metodología participativa fue desarrollada gracias a la respuesta de los grupos estudiantiles, los cuales expresaron sus ideas e inquietudes por medio de dos técnicas teatrales específicas: teatro del oprimido y creación colectiva. La primera apeló a la democratización del arte, mediante técnicas que analizan las relaciones de poder inmersas en la sociedad y sus posibles vías de solución desde la participación colectiva; en otras palabras, "Es una estética que ofrece analizar nuestro pasado, para poder inventar un futuro, en vez de esperar por él" (Boal, 2001, p. 12). Así, dicha corriente de educación popular se propone analizar el pasado, presente y posible futuro de determinados grupos, según sus problemáticas sociales inmediatas en el contexto latinoamericano.

La segunda técnica consistió en una vertiente de estímulo y creación, a partir de la validación de las ideas que un colectivo propone en función de una misma línea de trabajo: "es un conjunto de personas que interactúan entre sí durante un periodo de tiempo y que se reconocen como interdependientes entre ellos en relación a un objetivo común, en este caso vinculado al arte y su divulgación" (Marín, 2007, p. 33). La horizontalidad y democracia, presentes en los procesos de escucha, espontaneidad creativa y fusión de propuestas artísticas, rompen la jerarquización de roles en los procedimientos artísticos latinoamericanos, representando una alternativa de trabajo en el campo del arte escénico. 


\section{Referencias}

Aulicino, J. (2006). Brecht: el teatro no cree en lágrimas. Recuperado de http://www. rebelion.org/noticia.php?id $=36573$

Barquero, J. y Chacón, M. (2011). En busca de una capacitación como facilitadores de Teatro Foro (tesis de licenciatura). Universidad Nacional, Costa Rica.

Boal, A. (1974). Teatro del Oprimido y otras poéticas políticas. Argentina: Ediciones de la Flor.

Boal, A. (1982). Técnicas Latinoamericanas de Teatro Popular. México: Editorial Nueva Imagen S.A.

Boal, A. (2002). Juegos para actores y no actores. España: Alba Editorial.

La comunicativa (CTO). (2010). Reflexiones en el Arco Iris del deseo. Recuperado de http://acomunicativacto.blogspot.com/2010/07/reflexiones-de-augusto-boal-enel-arco.html

Brecht, B. (1957). Breviario de Estética Teatral. Argentina: Ediciones La Rosa Blindada.

Brecht, B. (1973). Escritos sobre teatro. Argentina: Ediciones Nueva Visión.

Center for Playback Theatre. (2009). (Documento electrónico). Recuperado de http:// www.playbackcentre.org

Compañía de Teatro Espontáneo. (2009). (Documento electrónico). Recuperado dehttp:// elcolectivo.wordpress.com/acerca-de/

Foucault, M. (1979). Microfisica del Poder. España: Las Ediciones de la Piqueta.

Freire, P. (1999). Pedagogía del Oprimido. México: Editorial Siglo Veintiuno.

Fuenmayor-Ávila, F. (2007). EL concepto del poder en Michael Foucault. Recuperado de: serbal.pntic.mec.es/ cmunoz11/avila53.pdf

Guiloff, C. (2008) ¿Qué es Teatro Espontáneo. Recuperado de http://www.catalinaguiloff.cl/content/view/303887/Que-es-el-TEATRO-ESPONTANEO.html\#content-top

Gutiérrez, S. (1979). Teatro Popular y cambio social en América Latina. San José: Editorial Universitaria Centro Americana.

Márcenes, E. (1977). El método de la creación colectiva en el teatro colombiano. Latín American TheaterRewiew, 11, 1-62.

Marín, T. (2007). Creación colectiva. Análisis comparado de los equipos de artes visuales en la Comunidad Valenciana de 1981 a 2000. Universidad Politécnica de Valencia. 
Rivera, H. (2009). Bertolt Brecht el visionario. Recuperado de http://200.21.104.25/artescenicas/downloads/Artescenicas1-1_6.pdf

Saura, J. (2007). Actores y actuación. Antología de textos sobre la interpretación. Volumen III. España: Editorial Fundamentos.

Savater, F. (2005). Fabricar humanidad (videoconferencia en encuentro "Los sentidos de la educación y la cultura), España.

Teatro Espontáneo. (2009). Primer encuentro español de intercambio en teatro espontáneo. 